\title{
On Planning and Managing the Preservation of Historical Buildings
}

\author{
Č. Jarský
}

The process of preserving and reconstructing historical buildings poses several specific questions and raises problems which must be solved in the planning and management stage of the building process - from questions of architectural and art-historical significance, via the future purpose of use of the building, links to the surrounding buildings, environmental questions, questions of cost, time analysis, and quality assurance problems. Many of these problems can be solved with the help of a computer model of the course of the rehabilitation and reconstruction of the building created by a construction technology network diagram. The CONTEC integrated project planning, management and quality control system based on these diagrams has been used for bidding, planning and managing the reconstruction process of several significant historical buildings in Prague and other cities.

Keywords: reconstruction, historical buildings, project management, planning, quality assurance, construction technology network diagram.

\section{Introduction}

Many historical buildings have been reconstructed in the Czech Republic in recent years, especially in Prague. In the planning and design stage of the reconstruction several specific problems have to be solved, and many considerations have to be taken into account in this decision process. The main questions are raised in the fields of architectural and art-historical significance, links to the surrounding buildings, environmental questions, questions of the future purpose of use of the building, technical problems of optimum choice of different constructions, cost and time analysis and problems of quality assurance and control. Some of these problems can be solved efficiently by creating a computer model of the flow of the building process of the reconstruction. The model must be based on an analysis of the construction technology of the reconstruction process, and must reflect all the main considerations and architectural, technical, technological and financial aspects of the building process. The user must be able to create and update the model very quickly, because especially when reconstructing historical buildings the conditions for the flow of the reconstruction process can often be changed, e. g., by the actual state of the load-bearing structure, discoveries of historical paintings, frescoes or archaeological remains, etc. Such discoveries have a significant influence on the continuation of the reconstruction process, especially from the point of view of the deadline. Therefore the CONTEC computer-based integrated project planning, management and quality control system, based on the construction technology network, has been used in recent years for planning and managing the reconstruction process of several significant historical buildings in Prague and in other cities.

The linkage to the quality assurance system appears right from the first stage of planning of the project [1]. It is desirable to be able to make further use of the documents submitted during the bidding process for actual management of the construction processes on site and for quality assurance of the whole project after a contractor has been selected. In order to make such evaluations as precise and quick as possible, an expert computer-based project planning and management system, named CONTEC, has been developed. CON-
TEC is capable of modelling very quickly not only the building process of the project itself, including an analysis of costs and other resources, but simultaneously the process of maintenance [2] and reconstruction needed in years to come, and even the process of demolition, if need be. The main aspects of the erection and maintenance process that need to be evaluated are the minimum costs during the lifetime of a building [3].

\section{What the model of the building process is required to provide}

The investor's feasibility study must answer some key questions, e.g., what the price of the project will be, what the time schedule and the course of the building process will be, and whether it is possible to keep to the required project deadline from the technological point of view. The total desired time of service and the quality level also have to be stated. It is desirable for the investor to be able to model some of the contractor's data about the building process of the project, especially what the actual costs of the project will be and therefore the resulting profit, how many specialist craftsmen will be needed, what sorts of machinery will be needed on site, and when, how the cash flow and finances will be managed, and how the quality of the project and its parts will be assured and controlled.

With the help of the CONTEC system, the investor and the contractor can simulate the proposed time and resource flow of the building process of the project on a microcomputer, even if the relevant topical data about the project in the planning stage is very poor. The more precisely the task is determined, the better the results that can be obtained from the model. On the basis of typical network diagrams and a database of construction processes, a model of the actual erection of a building and a model of its maintenance and reconstruction can be automatically created. After completing the model the investor and the contractor can make their decisions about actual resource allocation in time, taking into account the whole time of service (including the influence of inflation), the necessary maintenance and reconstruction cycles, and the durability of the structures used in the buildings. The model of the building, maintenance and reconstruction 
process is based on the main documents of the construction technology design [4].

\section{On the methodology and basic documents for construction technology design}

The methodology for automated creation of the basic documents for the construction technology design is described in [5]. The main documents in construction technology design include files of technological standards, sometimes referred to as technological analysis sheets or programmes, and network diagrams. The close links between these documents used in the CONTEC expert system enable us to elaborate bar charts, line-of-balance graphs, allocation graphs of various technological and economical resources, and quality assurance checklists. In the past, these documents - technological standards (programmes) and network diagrams - were mostly processed subsequently, and separately. Their close relationship with construction technology was often disregarded, and network diagrams elaborated without consistent technological analysis contained a number of errors which made them useless for construction project control, leading to loss of money, time and quality. Quality assurance checklists were not usually elaborated at all, or were elaborated by a separate division with no connection to the actual flow of the building process. The simultaneous elaboration of technological standards, network diagrams, cost analysis and quality assurance checklists used in the CONTEC expert system eliminates the processing of network diagrams without a technological analysis, and enables use to be made of the close link between technological standards and documents for quality management in the project.

The technological standard (technological analysis sheet or programme) determines the technological structure of the production process (the sequence of construction processes, volume of production, labour and cost consumption, number and type of workers or machines, etc.). According to the calculated network diagram the technological standard includes a bar chart, which indicates the time structure of the production process. A technological scheme showing the spatial structure of the process is usually added. The connection between the time structure and the spatial structure of the building process is shown in the line-of-balance graph. The quality assurance checklist, which is automatically created according to the technological standard, consists of instructions for performing the quality checks of the resulting product at each stage in the construction process.

The values for the duration of the processes and the minimum working space necessary can be used to make (with regard to the direction of the course of the processes) a critical approximation of the construction processes. These processes can then be immediately linked optimally in the construction technology network diagram method, taking into account the quality of the resulting products of the construction processes. Thus all the documents mentioned above after the network diagram calculation depict floats in the construction processes. The floats are subsequently used to optimise the building process, taking into account the limited resources in different time periods.

\section{Basic facts on links in the construction technology network analysis method}

The construction technology network analysis method used by the expert system was designed for simultaneous evaluation of technological standards and network diagrams, and for optimal linking of the construction processes (most efficient use of working space on site for efficient economical and safe performance of construction processes, including technological pauses [5]). The network analysis method uses the activity-on-node network diagram. All four types of links of activities introduced in the precedence graph method (finish - start, start - start, critical approach and finish - finish), $[6,7]$, are also included in the construction technology network analysis method. The main disadvantage of the precedence graph method is the need to know the actual values of the lag times between each two activities that are linked together, and their duration, while creating the network diagram. This would make concurrent evaluation of the technological standard and of the network impossible.

Therefore the construction technology network analysis method introduces the 5th type of link, the construction technology link. This results from the condition of release of the minimum working space on a structure by the previous work gang, so that the following work gang can start as soon as possible. The lag time is not given by a certain time value but it is calculated by the computer according to the duration of linked activities and according to the spatial structure of the building. This is represented by the working space index $\mathrm{f}$. This index is determined by the ratio of the minimum working space needed for the gang divided by the total working space in the building. For example, in an 8-storey administrative building the usual minimum working space is 2 floors, so the working space index $\mathrm{f}$ is $2 / 8$, i.e., $25 \%$, see Fig. 1 . Introducing this link in the CONTEC method not only simplifies the input of the data of the network diagram but also permits extensive formation and utilisation of typical network dia-

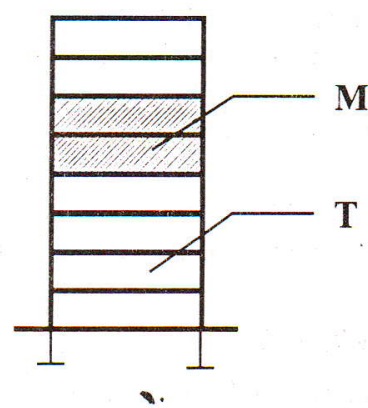

$\mathrm{M}$ - minimum working space

$\mathrm{T}$ - total working space available

$\mathrm{f}$ - working space index

$\mathrm{f}=\frac{\mathrm{M}}{\mathrm{T}} \cdot 100[\%]$

Fig. 1: Working space index

grams as computer files for the erection, maintenance and reconstruction of various sorts of buildings. These can be modified according to the spatial structure of the actual building. There are usually only three main types of working space for different activities on site ( $f_{1}$ for underground structures or works on the roof, $f_{2}$ for erection and plumbing, $f_{3}$ for finishing works). Thus only three values of the main working space indices are sufficient to evaluate practically all technologi- 
cal constraints in the building process. In a typical network diagram the values of the working space indices are given parametrically. While stating data about the actual building, a typical network diagram can be modified stating only the three main working space indices.
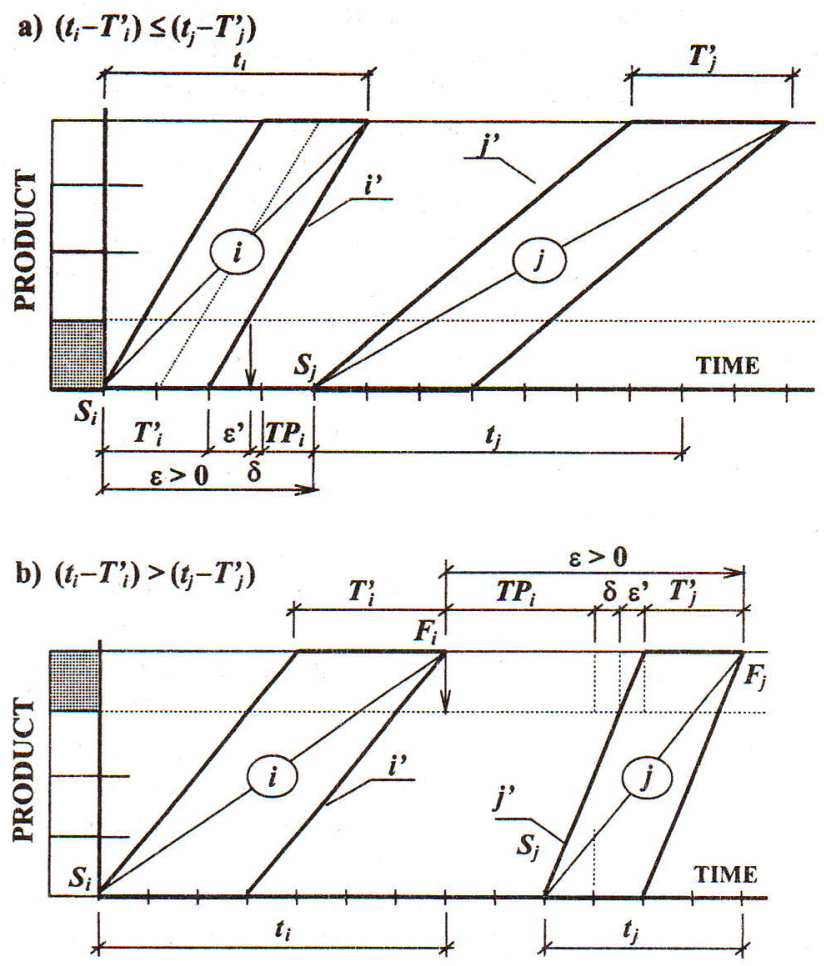

Fig. 2: Principle of the construction technology link

The situation where two processes of technological stage $i$ and $j$ are linked is illustrated in the line-of-production graph on Fig. 2 a, b. Each process of a technological stage (e.g., foundation, superstructure, etc.) consists of several construction processes (work gangs, e.g., formwork, reinforcement, concrete laying, etc.). Values $t_{i}$ and $t_{j}$ represent the duration of processes of technological stage, $T_{i}$ and $T_{j}$ their time of launching, $T P_{i}$ the technological pause after completing activity $i, f_{i j}$ is the working space index. In the first case (Fig. 2 a), if the last construction process in the preceding process of technological stage $i$ is shorter than the first construction process in the following process of technological stage $j$, the lag time $\varepsilon$ can be automatically calculated according to formula (1)

$$
\varepsilon=\left(t_{i}-T_{i}^{\prime}\right) \cdot f_{i j}+T_{i}^{\prime}+T P_{i}+\delta
$$

Value $\delta$ rounds the lag time to whole time units, so that the relevant work gang will start its work at a certain time unit in the morning. If the first construction process in the following process of technological stage $j$ is shorter than the last construction process in the preceding process of technological stage $i$, (Fig. 2 b), then the lag time $\varepsilon$ is calculated according to formula (2)

$$
\varepsilon=\left(t_{j}-T_{j}^{\prime}\right) \cdot f_{i j}+T_{j}^{\prime}+T P_{i}+\delta .
$$

In the time analysis of the network diagram using the construction technology link, the start of the following activity $j$, denoted $S_{j}$, can be calculated during the forward calculation according to formula (3), and the completion of the preceding activity $i$, denoted $F_{\mathrm{i}}$, can be calculated during the backward calculation of the network diagram according to formula (4).

$$
\begin{aligned}
& S_{j}=\max \{ {\left[S_{i}+\left(t_{i}-T_{i}^{\prime}\right) \cdot f_{i j}+T_{i}^{\prime}+T P_{i}+\delta\right] ; } \\
& {\left.\left[S_{i}+t_{i}-t_{j}+\left(t_{j}-T_{j}^{\prime}\right) \cdot f_{i j}+T_{j}^{\prime}+T P_{i}+\delta\right]\right\} } \\
& F_{i}=\min \left\{\left[F_{j}-t_{j}-T P_{i}+\left(1-f_{i j}\right) \cdot\left(t_{i}-T_{i}^{\prime}\right)-\delta\right] ;\right. \\
& {\left.\left[F_{j}-T_{j}^{\prime}-T P_{i}-f_{i j} \cdot\left(t_{j}-T_{j}^{\prime}\right)-\delta\right]\right\} . }
\end{aligned}
$$

The construction technology network analysis method goes on to introduce the 6th type of link, the flow link, which results from the condition of the continuous course of a construction process on different products, e. g., sections, buildings, etc. The 7th and 8th types of link, partial links, describe the condition that a following activity may start (or must finish) after the completion of a certain part of the previous activity, or vice versa. These links are determined by partial link indices that represent the ratio of the duration of the finished part of the previous activity divided by the total duration of the previous activity (type 7), or the ratio of the duration of the unfinished part of the following process divided by the total duration of the following process (type 8 ). If this index is negative it represents the same ratio but for the following (type 7) or preceding (type 8) activity. With the use of the flow link, modified typical network diagrams or evaluated network diagrams of buildings can be automatically linked into a larger network that may represent the building process of the whole project, consisting of many buildings, e.g., a housing estate, an industrial plant, or its maintenance or reconstruction. In this case the flow lins are generated by the system in the activities performed by specialised work gangs that proceed continuously from one building to another. The network diagram can be calculated on a deterministic or stochastic basis, [5].

\section{Modeling the erection, maintenance and reconstruction of buildings}

The main condition for modelling the erection, maintenance and reconstruction process is a statement of the task and the intentions of the investor and architect and the links to the external environment. In the very first stage we usually know, e.g., that there is an intention to reconstruct certain buildings with a certain built-up area. There are some propositions and drafts about the layout, future purpose of use, level of quality and durability, the structures used, and the deadline for the building process. Later the investor usually has a certain level of design of the project, including the important bill of quantities.

Then, a database for rapid modelling of the building process is put together. This database consists of the main data about all construction processes affecting the technological structure of the work gangs. This includes the main facts about the deadlines, productivity of labour, price of the product, number of workers, technological pauses and 20 other financial and technological resources (material costs, wages, costs for machinery, overheads, average profit, machinery, materials, skilled workers, etc.). For automatic modelling of the maintenance and reconstruction data about the average 
durability of the material, the number of maintenance cycles until reconstruction of the product and marks of the typical network diagrams for maintenance and for reconstruction are also included. In order to enable quality assurance checklists to be made quickly, another database of checks on the quality of the resulting products (what must be controlled, how, according to which standards, etc.) has been created. The quality check database is linked with the database of construction processes [8].

A typical network diagram of a reconstruction or maintenance process as a computer file contains data about the sequence and linkage of the construction processes. It is preferable to use the construction technology link stated parametrically as much as possible, or other sorts of links with the lag time equal to zero. Under these conditions, typical network diagrams can easily be modified according to the spatial structure of an actual building. The volume of production and costs and the price of all activities are also included. These are related to an appropriate custom-made unit of measurement, usually $\mathrm{m}^{3}$ of build-in space or $\mathrm{m}^{2}$ of reconstructed area in the case of a reconstruction. As stated above, the typical construction technology network diagram can be modified according to the spatial structure of the building process by using the three main minimum working space indices.

When the user simulates the building or reconstruction process, the first stage is to call up the typical network diagram for a certain type of building, then to modify it by stating the actual main working space indices, and the computer then generates the first draw model of the erection process, including the time and cost analysis data, which are transferred from the database of construction processes. Thus, the user can get the first model much more quickly than by using classical project management systems, which require the network diagram to be created by adding the relevant activities one after another and stating their duration, resources and links. The created model has to be defined with greater precision, taking account the facts known about the building. It is known that $80 \%$ of the price and costs is influenced by just $20 \%$ of activities. The production volumes of these significant processes have to be stated according to the construction design. The production prices, labour consumption and required resources are calculated automatically on the basis of the database of activities. If the exact bill of quantities is available, its values can be automatically transferred into the model. After the calculation of the network diagram the user receives the earliest and latest dates for starting and completing all activities. By changing the number of workers in the gangs or by changing the tension index of time standards the duration of activities and thus the whole network diagram can be modified. Activities of all sorts (not only those from the database) can be entered into the network. After making these models for all buildings that are included in the project, a network diagram of the whole project can be made by connecting the partial networks and linking them together with flow links in the case of specialised work gangs working continuously in linked buildings creating a building flow.

Thus, it is not necessary to create the network diagram individually from the very beginning for each project. The CONTEC system enables a model of the building process of the project to be built up very quickly from prefabricated sections and typical network diagrams of different buildings, and it can be defined easily and with greater precision according to the facts gained from the investor's data. This can easily be updated if various conditions change. The network can be automatically recalculated with a view to keeping to the deadline of the project. The system then selects activities that have to be shortened, by adding a certain number of workers or by increasing the intensity of the work, while keeping to the technological rules, and all links of the network. The system enables the calculated network diagram to be printed in different forms (technological standards, bar charts, line-of-balance graphs, resource allocation graphs of price, costs and cash flow, labour consumption, work force requirements, etc.), in Czech, English, Italian or Russian. Even in the very first stage of the plan the quality assurance checklist can be created by using the database of quality checks. The particular network diagram can then be aggregated into the higher information level of the technological stages, steps of completion or into the level of buildings.

On the basis of the model of the erection of the building, a complete model can be created which includes not only the erection but also maintenance and reconstruction. Nowadays this can be done interactively on the computer with the help of the databases and typical network diagrams as models of maintenance and reconstruction related to corresponding processes, taking into account the durability of the products. A computer program has been recently been developed for this purpose, see Fig. 3. The user will have to state the maximum lifetime of the building, indices of inflation and the operating costs for the years to come. Then the computer will be able to choose relevant maintenance cycles Ml - Mx for different construction units and reconstruction models, and will sort them in time and automatically connect them into a network diagram. The time periods of individual maintenance cycles represented by the arrows in Fig. 3 are read from the database of construction processes, as are the marks of the

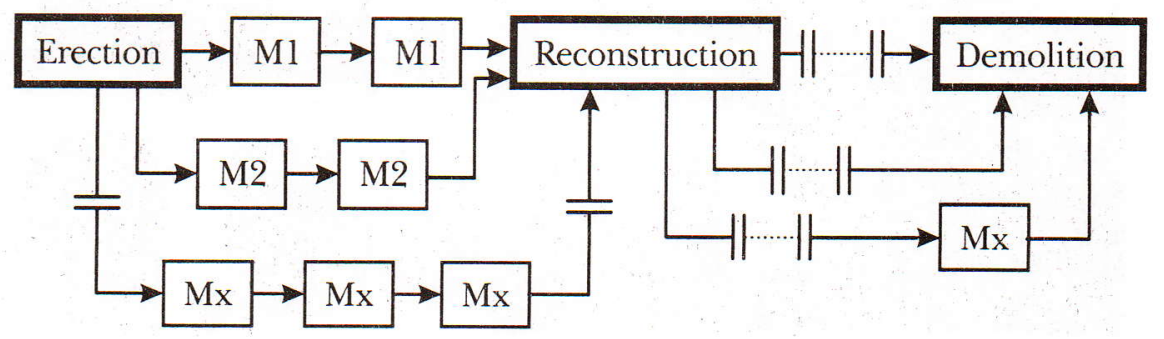

Fig. 3: Scheme for automatic creation of maintenance and reconstruction cycles 
relevant typical network maintenance (M1 - Mx) diagrams. After the evaluation of the complete network diagram, the costs and other financial resources for maintenance, reconstruction, operating expenses and costs, for demolition if need be, are recalculated according to the inflation rate.

The user can make changes in the original erection model, especially in choosing structures with different price and durability, and the computer then generates the corresponding maintenance and reconstruction variant. As a simultaneous time-cost analysis is always done automatically, the user can minimise the total expenses for erecting, operating, maintaining and reconstructing the building at any time. Naturally, all data included in the model can be interactively edited and recalculated.

All documents that are generated on the basis of the construction technology network graph can easily be updated according to the actual completion of construction processes on site at a certain date. If there is a delay, the system suggests what measures are to be taken in order to keep to the final deadline of the project. At the same time it keeps to the technological rules of the building process. This can be visualised in the comparative bar chart, where the updated version of the building process, drawn in bigger lines, is compared in a single document with the planned flow of the process. Critical activities are drawn in red, non-critical activities in green, and delayed activities in blue. On the basis of the recalculated network diagram, the line-of-production graph can be automatically redrawn on the plotter. The outputs from the system are used for evaluating the operational plans on site and for operational registration with the link to the invoicing agenda. The operational registration files from the invoicing system can be used for automatic updating of the network diagram in the CONTEC system and then for recalculating the deadlines for the activities and for the operational plan. A new resource allocation balance results from the updated model of the building process. Quality assurance checklists are updated simultaneously in a similar way, on the basis of quality checks.

\section{Examples of use on site}

The main documents related to construction technology and cost analysis created as described above can contain a model of the building process of the project that includes all necessary data for checking and managing the building process and for balancing the resource allocation. Many cases of reconstruction of historical buildings in the Czech Republic and Slovakia have been prepared and managed in this way. One particularly interesting case controlled by the CONTEC system was the reconstruction of 18 Renaissance houses with Gothic cellars in the Ungelt area in Prague Old Town. The middle of the area is the Týn Court, which is surrounded by 11 houses. The other 7 houses are situated nearby. In the planning stage a feasibility study was worked out which determined the optimum use of all the space from the architectural, historical, technological and financial points of view. All vaulted ceilings were saved and the wooden ceilings were reconstructed. There are many beautiful architectural details in these buildings (stone portals, staircases, sgraffito facades, etc.). A part of one of the finished buildings is illustrated in Fig. 4. New built-in units (windows, doors) were produced on the basis of the old photographs and paintings of the area. Project management documents based on the construction technology network analysis were elaborated to visualise the building process divided into construction processes.

Another interesting example of the use of the CONTEC system for modelling and cost assessment of a reconstruction process is the Toscano Palace near Prague Castle, see Fig. 5. This Renaissance palace belongs to the Czech Ministry of Foreign Affairs. The main purpose of the reconstruction was to modernise especially the internal equipment of the building while conserving significant architectural and historical details, such as the portals, towers, facade and courtyard. Many old frescoes were discovered in the course of the reconstruction, and these had to be restored. In this case the model of the reconstruction process had to be regularly updated

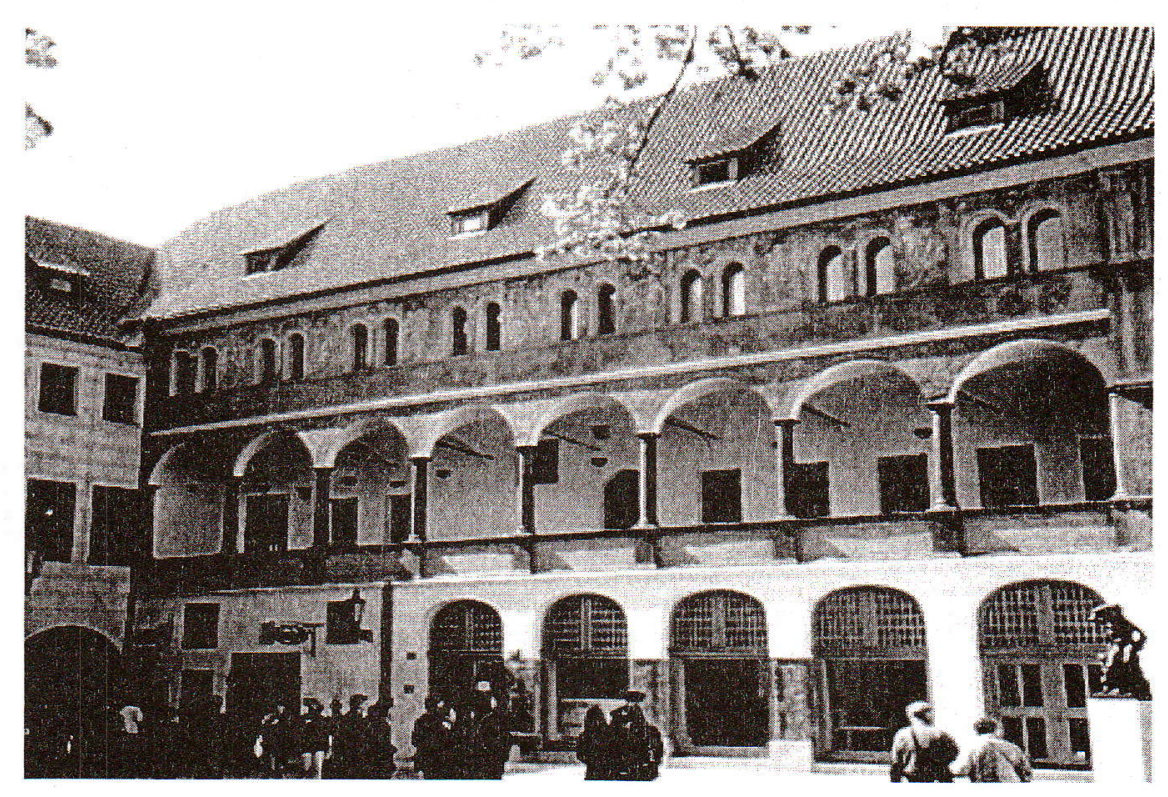

Fig. 4 Part of the reconstructed Týn Court in Prague 


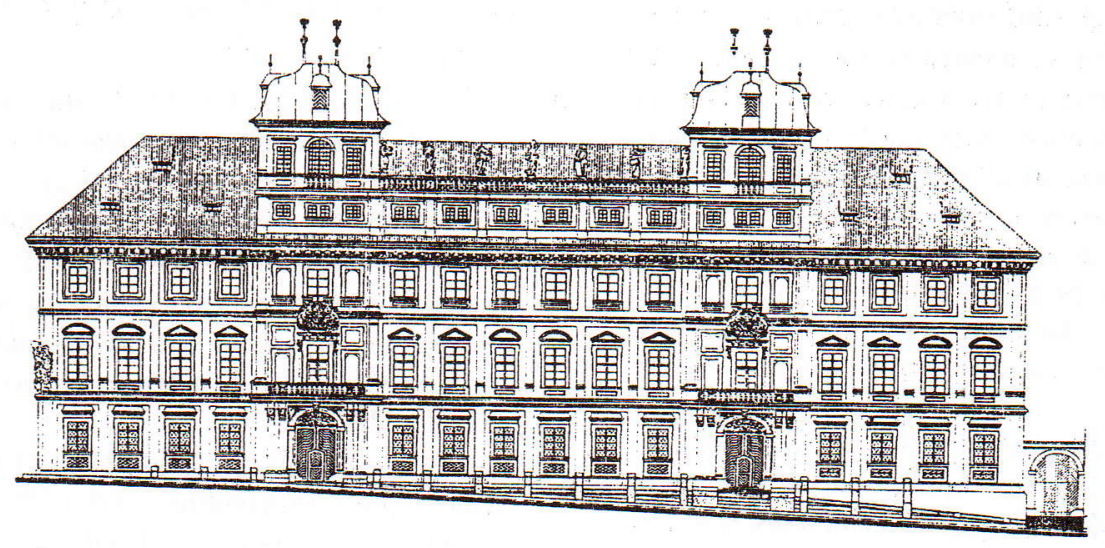

Fig. 5: Toscano Palace in Prague - western facade

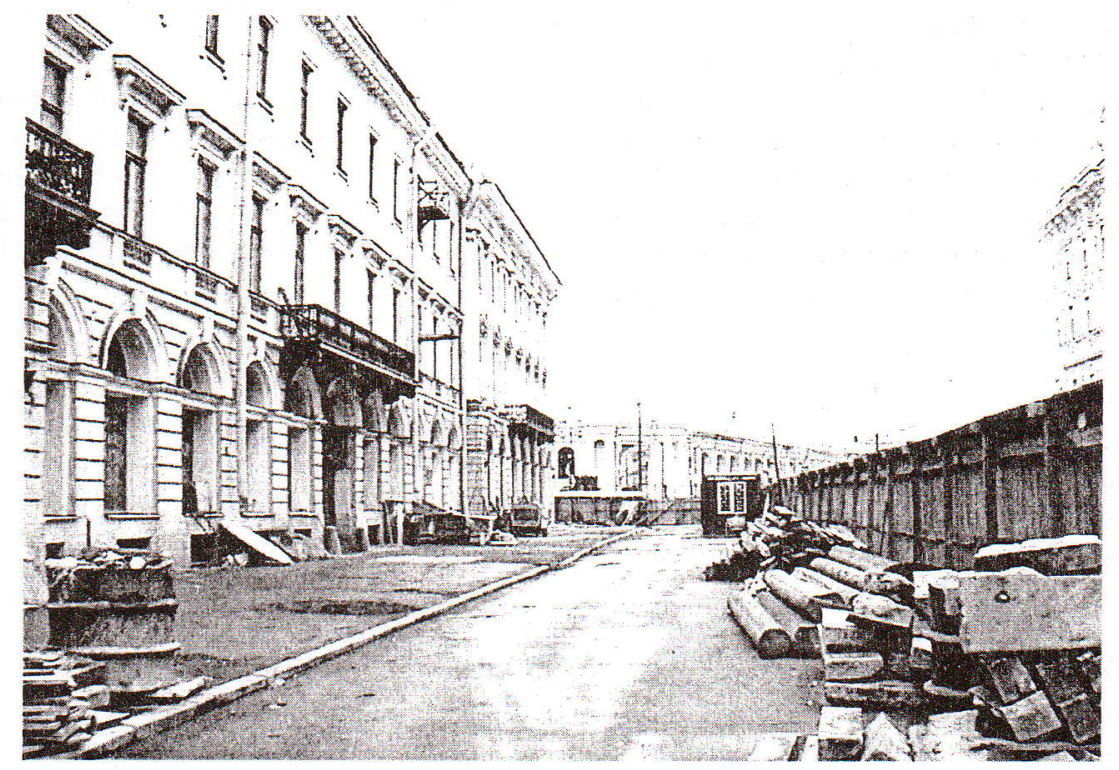

Fig. 6: Promstroibank St Petersburg, Russia - north-west facade

(approximately once a month). The main significance of the network model lay in its ability to take into account the delays caused by these discoveries and due to other changes, and to calculate the measures to be taken to keep to the final deadline of the project.

Another example of a time and cost analysis performed by the CONTEC system is the reconstruction of the Industrial and Construction Bank building on Nevsky Prospect in St. Petersburg, Russia. This project is planned for completion in summer 2003. The north-west facade of the building is illustrated in Fig. 6. The building was originally constructed at the end of the $18^{\text {th }}$ century, but completely burned down in 1993 . In this case, the beginning of the reconstruction was of crucial importance. There are very difficult ground conditions on this site, because it lies below the water level of the river Neva. The load-bearing walls have to be underpinned by oblique piles, new diaphragm walls have to be built and many injections, and much ground consolidation have to be performed. The south-east wing of the building will be completely demolished and then erected in a new form. All ceilings will be demolished and rebuilt. A new glazed steel roof structure will be built, and all necessary technological equipment, including safes and computer systems for the bank, have to be replaced. In the construction technology and cost analysis the climate and weather conditions have to be taken into account, as they may have a very negative influence on the building process.

\section{Conclusions}

The main construction technology design documents created with the help of the CONTEC system can form a model of the building process of a project that includes all necessary data for control and management of the building, maintenance and reconstruction process. This system enables the creation of a building process model with appropriate cost assessment, and time-cost analysis about 50 times more quickly than current project management systems. It can take into account all specific attributes, links and constraints of the reconstruction process for historical buildings. The docu- 
ments can thus be used as a part of a feasibility study, bid, construction technology design and operative plan for project management of the erection or reconstruction process itself. This model can be updated in accordance with the bill of quantities or the cost estimation. Afterwards a quality assurance checklist can be automatically created. All documents generated by the system can easily be updated on the basis of actual completion on site at a given date. If there is a delay, the system suggests what measures are to be taken in the future in order to keep to the final deadline of the project. All documents can be automatically translated into Czech, English and Russian.

The system can model the costs for the necessary maintenance and reconstruction process throughout the lifetime of the building. With the regularly updated databases, the user can model and choose the best construction unit variant according to his goals and requirements, even in the very first stage of planning.

The system can be used on IBM PC compatible computers under Windows 9x, ME, NT, 2000 or XP operational systems. At present the CONTEC system, linked with various cost estimation systems, is in use in more than 350 investment and contracting firms in the Czech Republic and Slovakia. The experience gained by users is very extensive, and it is used on an ongoing basis for improving and innovating the system, especially in the field of automatic modelling and planning of the regular maintenance of buildings.

\section{References}

[1] Gašparík, J.: Quality Management System in Construction Firm. Proceedings of International Conference Developments in Building Technology 1996, Faculty of Civil Engineering of the Slovak Technical University Bratislava, Slovakia, p. 40-44.

[2] Rutter, D. K.: Effective Maintenance Management from a Rational User Perspective. International Scientific Conference Proceedings STU Bratislava, Slovakia, 1998, p. 237-242.
[3] Zapletal, I.: Bedeutung der Lebensdauer von Bauobjekten bezüglich der Gesamtkosten. Technische Universität München, Germany, 1995.

[4] Jarský, Č., Kozlovská, M, Vrána, P.: Tvorba nabidek a stavebně technologické projektováni pomoci mikropočitače (Bidding and Construction Technology Design with the Help of Microcomputers). Faculty of Civil Engineering, Technical University, Košice, Slovakia, 1993, p. 192.

[5] Jarský, Č.: Automatizovaná připrava a ř́zení realizace staveb (Automated Preparation and Management of Realization of Projects). CONTEC Kralupy n. Vitavou, Czech Republic, 2000, p. 222.

[6] Jarský, Č.: Modelling of the Building Process by a Computer Expert System. Proceedings of the $8^{\text {th }}$ International Conference on Computing in Civil and Building Engineering 2000, Stanford University, Stanford, California (USA), ASCE Reston VA 2000, p. 566-573.

[7] Ahuja, H. N.: Construction Performance Control by Networks. Wiley, N. Y., USA, 1976.

[8] Popenková, M.: Viv jakosti stavebního díla na tvorbu výrobniho procesu (Influence of the Quality of the Building on Creation of the Production Process). Proceedings of the $10^{\text {th }}$ International Conference Quality, 2001, Dům techniky Ostrava (Czech Republic), 2001, p. E40-E44.

Assoc. Prof. Čeněk Jarský, DrSc., Ph.D.

phone: +420315726910

+420224353590

e-mail: jarsky@contec.cz

jarsky@fsv.cvut.cz

Department of Technology of Structures

Faculty of Civil Engineering

Czech Technical University in Prague

Thákurova 7

16629 Prague 6, Czech Republic 